conditions of temperature, acid concentration, etc., similar to those of the standardization.

The amount of phenolphthalein used should be the same in each determination. An excess of the indicator causes low results. It has been noted in cases of alums, where iron does not interfere, that best results are obtained with three or four drops of phenolphthalein solution. Larger amounts of indicator are necessary if iron is present, in order to detect the end point.

COMBINED SULFURIC ACID-Provided no free acid is present, the combined acid is calculated from the titration for combined alumina. The titration multiplied by $0.72=$ combined sulfuric acid. viz., factor 2.8792 divided by 4 . Should free acid be present, as determined by the first procedure outlined, its equivalent should be deducted from both the alumina and combined acid. This is best done by subtracting the equivalent volume in terms of $N / 2$ solution from the total volume titration before dividing by 4 to obtain percentage of $\mathrm{Al}_{2} \mathrm{O}_{3}$ or multiplying by $0.7^{2}$ to get combined $\mathrm{H}_{2} \mathrm{SO}_{4}$.

EXAMPLE-Titration of $N / 2$ alkali due to free acid $=$ 2.2 cc. (Ist method).

Total titration of the hot solution (and method) $=$ $80.6 \mathrm{cc} . \mathrm{NaOH}$

The $80.6-2.2=78.4$ and 78.4 divided by $4=$ I 9.6 per cent $\mathrm{Al}_{2} \mathrm{O}_{3}$ or 78.4 multiplied by $0.72=56.45$ per cent combined $\mathrm{H}_{2} \mathrm{SO}_{4}$.

Free acid $=2.2$ divided by $4=0.55$ per cent $\mathrm{H}_{2} \mathrm{SO}_{4}$.

Sulfuric acid combined with the fixed alkalies is not titrated.

\section{EXPERIMENTAI DATA}

INFLUENCE OF IRON-Iron is invariably present in aluminum salts in ferric or ferrous form, generally a combination of the two. The amount seldom exceeds 0.8 per cent $\mathrm{Fe}$ so that comparatively large amounts of iron need not be considered here. Since the combined acid of iron in either state of oxidation titrates readily, this impurity will cause an appreciable error unless allowance be made for the amount present. The following results were obtained on a mixture of pure potash alum with varying amounts of iron as indicated, this impurity being added as ferric and ferrous sulfate. The quantity of alum taken was suffi cient to give a titration of over $69 \mathrm{cc}$. of standard alkali. The factors 0.64 for ferric and 0.47 for ferrous iron to alumina were used as recommended in the method.

\begin{tabular}{|c|c|c|c|}
\hline $\begin{array}{l}\text { Added iron } \\
0 \\
0.1 \% \mathrm{FeO} \\
0.5 \% \mathrm{FeO}_{3} \\
0.0 \% \mathrm{FeO} \\
0.1 \% \mathrm{FeO} \\
0.5 \% \mathrm{FeO} \\
1.0 \% \mathrm{FeO}\end{array}$ & $\begin{array}{l}\text { Titration } \\
69.4 \mathrm{cc} . \\
69.8 \mathrm{cc} \\
70.85 \mathrm{cc} . \\
72.5 \mathrm{cc} \\
69.6 \mathrm{cc} \\
70.65 \mathrm{cc} . \\
71.5 \mathrm{cc} .\end{array}$ & $\begin{array}{c}1 / 4 \text { Titration } \\
17.35 \mathrm{C} \\
17.45 \\
17.72 \\
18.12 \\
17.40 \\
17.66 \\
17.88\end{array}$ & $\begin{array}{c}\text { 1/. Titration } \\
\text { corrected for iron } \\
17.39 \\
17.41 \\
17.48 \\
17.35 \\
17.43 \\
17.41\end{array}$ \\
\hline
\end{tabular}

It is evident that with $1 / 1$ the titration representing per cent, iron present either as ferric sulfate or ferrous sulfate up to one per cent in terms of iron oxide causes no serious error, provided the corrections are applied for the titration of the iron. Ferric iron tends to cause high results.

The fact that ferric and ferrous sulfates are titrated is shown by the results given below. Ammonium sulfate and persulfate are also titrated, the fixed alkalies are not. Results are given in terms of the acid calculated from the titration.

\begin{tabular}{|c|c|c|}
\hline 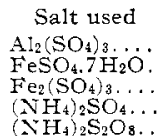 & 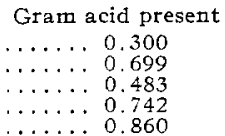 & $\begin{array}{c}\text { Gram acid calculated } \\
0.299 \\
0.636 \\
0.612 \\
0.658 \\
0.850\end{array}$ \\
\hline
\end{tabular}

Ammonia is expelled in the boiling solution as the alkali replaces it in combination.

Ferrous hydroxide occludes phenolphthalein indicator to a point of saturation. For example, it was found that one gram ferrous sulfate with excess $\mathrm{NaOH}$ would completely absorb $25 \mathrm{cc}$. of the indicator preventing it from giving the desired color with caustic, whereas an excess of the indicator above this amount produced the pink color with the excess caustic.

The following results were obtained with three standard aluminum salts by the usual gravimetric methods, and the results checked by the volumetric procedures outlined:

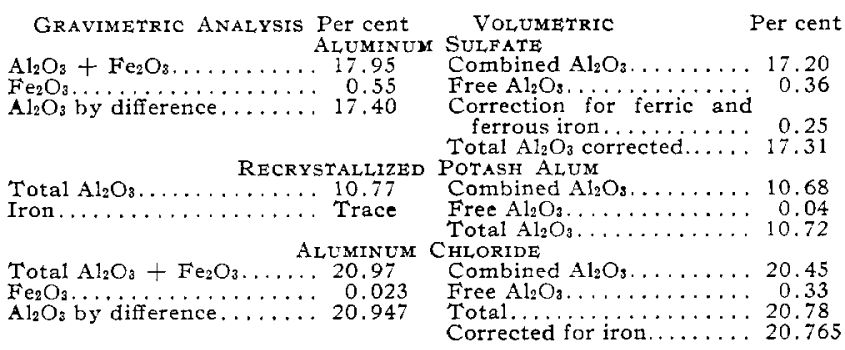

The end point is sharp when iron is absent, but with amounts of iron exceeding I per cent the color of the precipitated iron hydroxide tends to mask the pink color due to the indicator. Ferric iron produces a reddish pink end point; with ferrous iron a purplish pink color is observed.

Four men working independently checked within $0.6 \mathrm{cc}$. in the titration for combined alumina, and within $0.1 \mathrm{cc}$. in the fluoride method for free alumina, making the limits of error due to the personal factor, O.I 5 per cent for total $\mathrm{Al}_{2} \mathrm{O}_{3}$ and 0.02 per cent for free $\mathrm{Al}_{2} \mathrm{O}_{3}$.

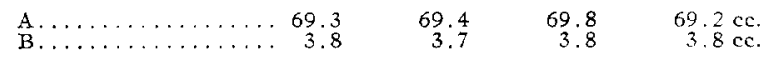

SUMMARY

Rapid volumetric procedures for determining combined and free alumina in aluminum salts, followed by experimental data showing reliability of the methods, are given. Impurities such as commonly occur in these salts do not interfere, with exception of iron, for which correction must be applied as stated. The methods are of special value for works control of liquors during the process of manufacture of aluminum salts, and the analysis of the finished product in daily routine analysis.

Research Department, GeNeral Chemical COMPANY LAUREL HILL, IONG ISLAND, $N, \mathrm{Y}$

\section{RECOVERY OF AMMONIA FROM WASTE LIQUORS}

By E. L. KNOFDLER

Received May 22, 1915

A recent investigation of waste products in the plant of the Welsbach Company brought to light a 
solution containing about I per cent of ammonia, which was being discharged into the sewer. The investigation showed that this solution consisted of a mixture of three ammoniacal solutions containing, respectively, the following percentages of free and combined ammonia:

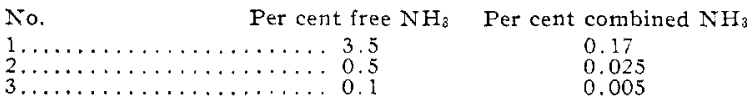

When mixed together, as they appeared when run to waste, the mixture approximated I per cent free ammonia and 0.05 per cent combined ammonia. The
In the selection and erection of the apparatus, the points of easy and inexpensive maintenance and operation were carefully considered, with special attention to low labor charges and small steam consumption.

With these points in mind the distilling outfit shown in Fig. I was so erected and set that the waste liquor fiows by gravity from the factory processes to a large iron tank set in the ground just outside the still house, from which it is pumped to the storage tank set above the column of the still. This pumping is the only handling of any liquor during the complete cycle of operations-the storage tank supplying the

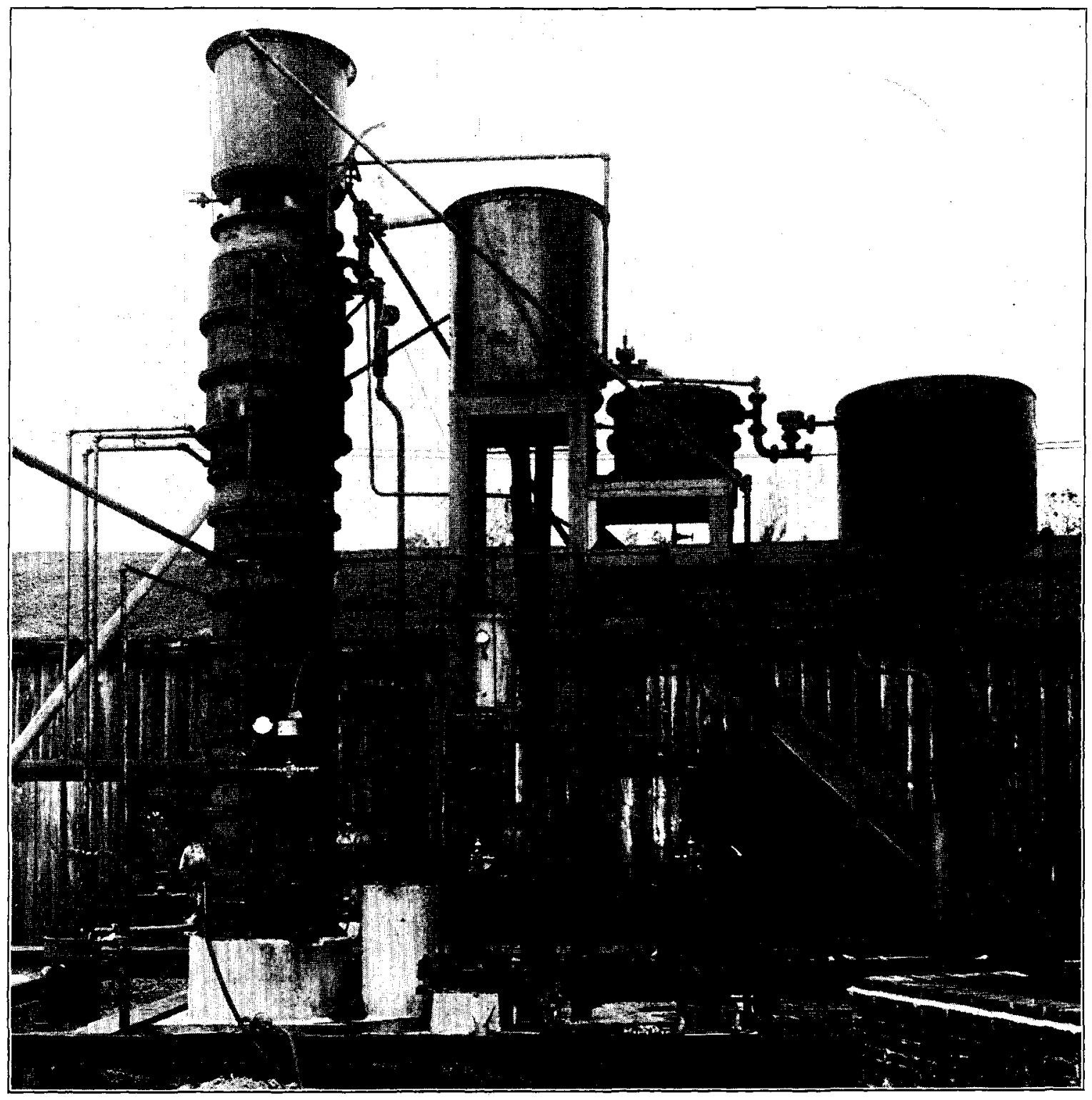

FIG. 1

solution was perfectly clear and recovery of the ammonia was found to be practicable by the usual methods of distillation.

The waste liquor was produced by the factory processes at practically a constant rate throughout the working day, and this consideration influenced the decision to recover by means of a continuous still. liquid at a constant head at all times, whence it flows by gravity through the washer, the coils of the heat exchanger, the heater and the still-the waste passing around the coils of the heat exchanger and then to the sewer. The ammonia vapors pass through the condenser and into the absorber, from which the freshiy distilled ammonia overflows into the storage 
tank. This tank is set at such a height that the fresh solution flows by gravity to the factory where it is available for use by simply opening a cock.

The steam supply for the still is automatically controlled, as is also the delivery of lime for release of the fixed ammonia, so that it is necessary for the attendant to look in only once each hour or two in order to see that the still is operating satisfactorily. The bulk of the heat in the waste liquor is saved by preheating the crude liquor in a heat exchanger and seal pot-the latter acting also as a constant fow automatic valve for the release of the waste. The consumption of lime is reduced to a minimum by keeping the milk sumption. The liquor then flows by gravity at a constant rate, down through the washer $B$ and then through the coils of the heat exchanger $C$, back up through the heater $D$, where it overflows through the pipe $E$, into the volatile still $F$, where the free a mmonia is driven off. The liquor then passes out through the pipe $G$ into the lime leg $H$ where it meets and is thoroughly mixed with the milk of lime, when it passes back into the still for fixed ammonia, $I$. Here the fixed ammonia is released and the waste liquor passes down and out around the coils of the heat exchanger by means of the pipe $L$, and overflows to the sewer.

The ammonia vapor passes up through the still,

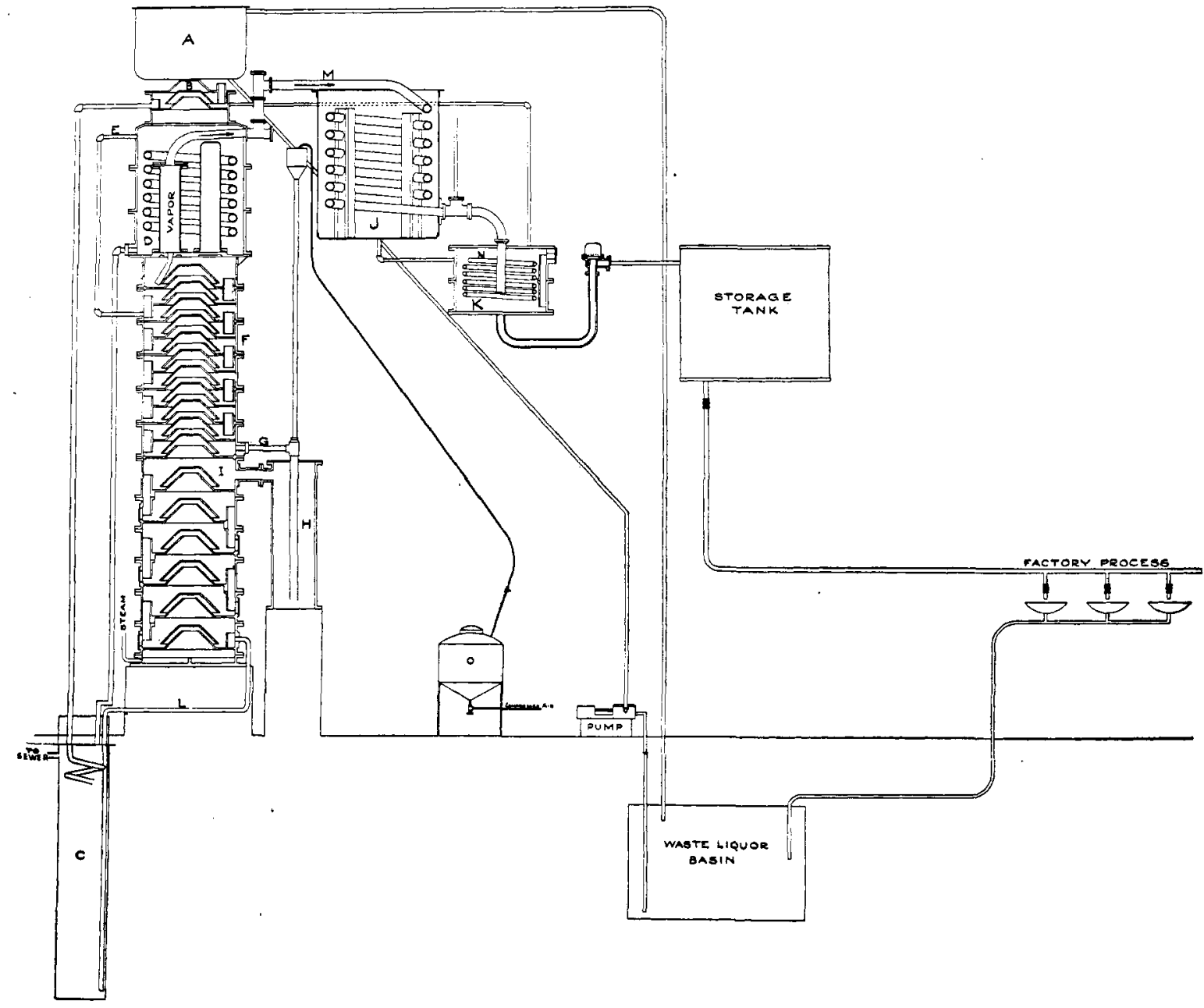

FIG. 2

of lime constantly and thoroughly stirred, and delivering it in small quantities and at frequent and regular intervals.

By these provisions for automatic operation, the cost of attendance and the handling of liquor, lime, etc., have been reduced to a minimum, the only still charges of any consequence being interest and depreciation, and coal for steam.

The operation of the still is extremely simple, and is as follows, references being to Fig. 2 :

The weak liquor is pumped to the storage tank $A$ by means of a small steam pump--the exhaust of which is led into the still to decrease the steam con- bubbling through the down-coming liquors in its passage from one section to the next, and then passes out through the coils in the heater $D$ and over into the condenser $J$ by the lead pipe $M$. Here the water vapors are condensed, and a part of the ammonia is absorbed. The condensate then flows down into the absorber $K$ where it is kept cool by means of water flowing through the coil $N$. Here the balance of the ammonia vapors are absorbed and the resulting ammonia solution passes over into the storage tank, from which it flows by gravity through lead pipes to the factory where it is used.

The milk of lime is made up and kept in an iron stir- 
ring tank, $O$, where it is agitated continuously by means of compressed air, which also operates the automatic valve, through which the lime is delivered to the still. The timing of this valve is regulated by a needle valve and by-pass between the top and bottom of a cylinder flled with kerosene, in which a piston descends and ascends. This makes it possible to supply the lime in small quantities and at frequent and regular intervals, making for uniform temperatures and regular operation.

Steam is supplied to the still through an automatic valve also operated by compressed air, the controller consisting of a thermostat, depending for its operation on the expansion or contraction of a liquid, the pressure thus generated serving to operate a small air valve which in turn controls the compressed air supply to a diaphragm valve through which steam is served to the still. The thermostat is adjusted to operate at the temperature of the top of the still, and serves to keep this temperature within a range of $2^{\circ} \mathrm{F}$. of the predetermined point. The concentrate runs about 28 per cent $\mathrm{NH}_{3}$ at all times and is diluted to the desired degree as used.

The cost of operation per romour day runs approximately as follows:

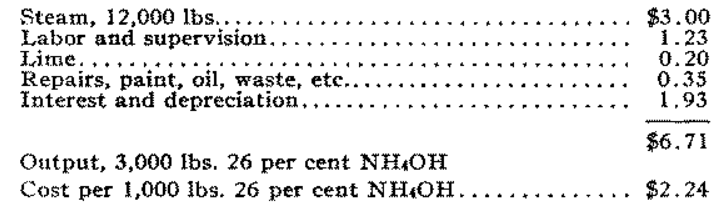

The outfit has proved to be simple in construction and easy to operate and the results more than come up to expectations.

Wrusbacr Co., Groverstzr, N. J.

\section{A NEW GLASS; AND AN APPLICATION OF THE LOW} REFLECTIVITY OF GLASS FOR RADIANT HEAT

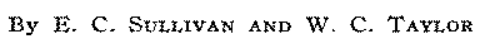

A glass has recently been developed which is unique among borosilicate glasses in that it combines very its melting and working. Some of the measured properties of the glass are as follows:

\section{Specific gravity 2.25 .}

Mean linear expansion coefficient $\left(19-350^{\circ}\right) 0.0000032$.

ATTACK BX REACENTS: Water at the boiling point dissolves several times as much from the best imported laboratory glass as from this glass.

SOFTENING POINT: A thread $\mathrm{I} \mathrm{mm}$. in diameter and 23 $\mathrm{cm}$, in length suspended vertically and heated through the upper $9 \mathrm{~cm}$. elongates of its own weight at the rate of $1 \mathrm{~mm}$. per minute at $800^{\circ} \mathrm{C}$.

Culinary ware made of the glass was found to bake food more rapidly than earthenware or metal. The reason for this lay in the case of the metal in the greater reflectivity of the metal for radiant energy. Magnus found that silver reflected $8_{3}$ to 90 per cent, glass only 6 to 14 per cent of the rays incident at an angle of $45^{\circ}$, while Hagen and Rubens ${ }^{2}$ give 98 to 99 per cent as the proportion of heat reflected by silver and Coblentz's $s^{3}$ curves indicate 3 to $r$ per cent as the reflection by glass. The following experiment, devised by Dr. J. T. Littleton, showed that this difference in reffectivity is of practical importance in the baking process:

A baking dish was silvered on the onter surface in alternate quarters and a cake baked in it in an ordinary kitchen oven over a gas flame. Where the cake had been protected by the metal coating the bottom after baking was light colored, sticky, and imperfectly baked while in the other quarters it was brown and well done. Fig. I shows the interior of the dish with the cake adhering to it over the silvered sections, also the cake as it was turned out bottom up with the quartering plainly visible.

Experiments showing that bread bakes faster in glass than in tin were made by baking equal quantities of dough in two glass bread pans and two tinned iron pans of the same internal dimensions. The metal pans had been in service for some time and their outer surfaces were somewhat tarnished. The pans were placed in the oven of a gas stove, the two glass pans diagonally opposite each other and the metal pans diagonally opposite each other. All four were left in the oven the same length of time. When taken

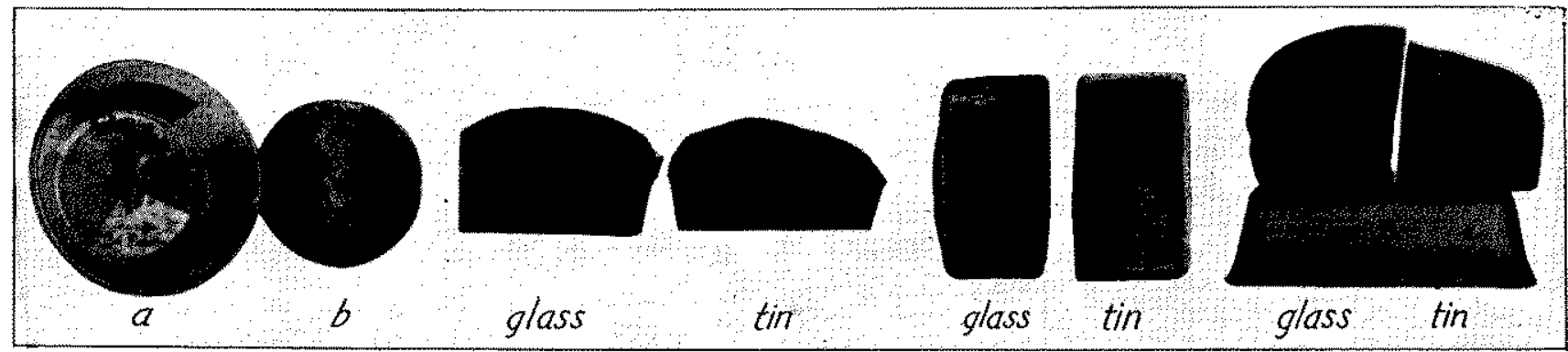

Fig. I-a, Dish Silvered in Quarters Outside Cake Has Adhered over the Silver Colored and Imperfectly Baked; Brown and Well-Done Elsewhere. b. Where Protected by Silver, Cake is Light

FIG. II
BREAD IN GLASS
AND TIN PANS
AS REMOVED FOM OVEN

low thermal expansion with great resistance to attack of reagents. It is of simple chemical composition, being free from heavy metals and metals of the magnesium-calcium-zinc group. Its characteristic properties are due, in part, to very high silica content which incidentally has necessitated special technique for

FIs. III
Borroms of Loaves
Bread from Tin Is
Lighter Colored

FIG. IV

HaLVED LOAVES

Loaf from Glass

Is Browner

out of the oven the crust in contact with the glass was browner than the corresponding portions of the crust in the metal pans. The bread in the glass had

\footnotetext{
x Poggendorf's Annalen, 138 (1869), 174.

'Drude's Annalen, 8 (1902), 1.

3 "Investigations of Infra-red Spectra," Part 4, p. 88.
} 